\title{
HEPATITIS C VIRUS GENOTYPE 3A: PREDICTIVE FACTORS ASSOCIATED WITH TREATMENT RESPONSE IN PATIENTS OF PESHAWAR.
}

1. MBBS, DCP, PhD Microbiology Assistant Professor

Department of Pathology.

Khyber Medical College, Peshawar, Pakistan.

2. FCPS Internal Medicine Associate Professor

Department of Medicine Shifa College of Medicine, Islamabad, Pakistan.

3. $\mathrm{PhD}$

Associate Professor

Department of Biosciences

COMSATS Institute of Information

Technology,

Islamabad, Pakistan.

4. $\mathrm{PhD}$

Professor and Dean

Institute of Basic Medical Sciences,

Khyber Medical University, Peshawa

Pakistan.

Correspondence Address:

Dr. Amina Gul

House No. 49, Sector J-4, Street 5 ,

Phase 2 Hayatabad Peshawar,

Pakistan.

dr.aminagul@gmail.com

Article received on:

$16 / 08 / 2018$

Accepted for publication:

$15 / 12 / 2018$

Received after proof reading:

$31 / 07 / 2019$

\section{Amina Gul', Naheed Gul ${ }^{2}$, ljaz $\mathrm{Ali}^{3}$, Jawad Ahmed ${ }^{4}$}

ABSTRACT... Background: Hepatitis $\mathrm{C}$ Virus ( $\mathrm{HCV}$ ) is a flavivirus responsible for causing chronic liver diseases including cirrhosis and hepatocellular carcinoma. Genome of HCV demonstrates marked genetic heterogeneity with seven confirmed genotypes and multiple subtypes. Diverse genotypes of HCV show differences with respect to their distribution, treatment strategies and response to antiviral therapy. Dual therapy with Conventional Interferon and Ribavirin in patients with chronic HCV infection is associated not only with various treatment related side effects but is also both physically and economically demanding. Therefore, identification of various patient and virus-related factors that can help predict response to antiviral therapy is extremely important in formulating the best therapeutic strategy for each patient either to continue or stop the therapy. Objectives: The present study aimed to determine Sustained Virological Response (SVR) in HCV genotype 3a infected patients that received combination therapy of Conventional Interferon (INF) and Ribavirin (RBV) and to investigate various factors that can help predict SVR. Study Design: Longitudinal Study. Settings: Institute of basic Medical Sciences, Khyber Medical University, Peshawar (IBMS, KMU). Period: July 2015 to September 2016. Material \& Methods: Treatment response was evaluated among $100 \mathrm{HCV}$ genotype $3 a$ infected patients that received combination therapy for 24 weeks. Various baseline parameters including hematological, biochemical and viral profiles were recorded. HCV genotype determination was carried out by type specific nested PCR based genotyping assay. Viral load was determined at baseline, at 12 weeks for Early Virological Response (EVR) and at 24 weeks of treatment for SVR. Viral RNA quantification was carried out by Real Time PCR. Results: Out of 100 patients, SVR was observed in $43 \%$ of patients; while $57 \%$ of the chronic HCV $3 a$ infected patients were NonResponders (NR). Mean age of patients was low $34 \pm 9.8$ among patients who achieved SVR as compared to patients with non-response $(41 \pm 10)$. The 24 weeks Alanine aminotransferase (ALT) levels were significantly lower among patients with SVR ( $p$-value $\leq 0.05$ ). Although statistically not significant, baseline viral load was higher in NR group ( $p$-value $\geq 0.05$ ), than those with SVR. Association of EVR with SVR was found statistically significant $(O R=2.8,95 \%$ $\mathrm{Cl} 1.2-6.4$, p-value $\leq 0.05)$. Conclusions: The current study indicated that pre and on-treatment monitoring of patients receiving anti-viral therapy is important for the management of patients with chronic HCV infection.

Key words: $\quad$ EVR, HCV 3a, Interferon, Ribavirin.

Article Citation: Gul A, Gul N, Ali I, Ahmed J. Hepatitis C Virus Genotype 3a: Predictive factors associated with treatment response in patients of Peshawar. Professional Med J 2019; 26(8):1315-1322. DOI: 10.29309/TPMJ/2019.26.08.3876

\section{INTRODUCTION}

$\mathrm{HCV}$ is an important health-care problem worldwide. ${ }^{1}$ The frequency of hepatitis $C$ virus associated disease is increasing, and no effective vaccine is so far available. ${ }^{2}$ Since the discovery of Hepatitis C virus in 1989, treatment of HCV has evolved significantly, but morbidity and mortality rates are still expected to rise in the coming years and more effective therapies are required. ${ }^{3}$ The ultimate aim of antiviral therapy is complete elimination of the virus defined as SVR. However, response to therapy is dependent on several factors, including viral genotype and patient characteristics. ${ }^{4}$ Seven major genotypes (1-7) of HCV show significant variation with respect to their worldwide distribution, treatment regimens and response to antiviral treatment. ${ }^{5}$ Until recently, the standard of care for patients with chronic HCV infection has comprised of a combination of standard or Pegylated interferon 
and Ribavirin, administered for 24 to 48 weeks depending on the HCV genotype. ${ }^{6}$ The response rates to INF based therapy are heterogeneous and HCV genotypes have been shown as the most important baseline variable influencing treatment outcomes. ${ }^{7}$ Reported SVR rates for patients infected with HCV genotype 1 and 4 infections are much lower $40-60 \%$ with standard treatment duration of 48weeks as compared to HCV type 2 and 3 infections with SVR rates of $60-80 \%$ and a relatively shorter treatment course of 24 weeks. ${ }^{8}$ HCV therapy has been revolutionized recently by the development of Direct Acting Antivirals (DAAs) affecting viral proteins and interfering with $\mathrm{HCV}$ lifecycle. ${ }^{9}$ DAAs in combination with PEG-INF and RBV have significantly improved treatment efficacy for HCV infection in terms of SVR. In spite of better treatment outcomes, the availability and affordability of DAAs in developing countries and more importantly its efficacy in different patient populations especially genotype $3 a$ patients are still major concerns. ${ }^{10}$ In Pakistan with HCV $3 a$ being reported to be the prevalent HCV genotype ${ }^{11}$, the combination of RBV with either Pegylated or conventional INF was previously used for chronic hepatitis $\mathrm{C}$ treatment where the primary goal of treatment was to achieve SVR. ${ }^{12}$ Accomplishing SVR greatly improves the clinical outcome of patients by reducing the progression to advanced liver diseases including cirrhosis and subsequent hepatocellular carcinoma. ${ }^{13}$ Although treatment with conventional INF and RBV increases the probability of attaining SVR by $50-70 \%$ and with addition of Sofosbuvir up to $83 \%$ for HCV-3a, the degree of antiviral response depends on a variety of patient and virus related factors and these may also fluctuate in various patient subpopulations. ${ }^{14}$ In addition to inadequate response rates antiviral therapies are associated with various side effects which remain an important consideration in the management of patients with HCV. ${ }^{15}$ Because of the suboptimal effectiveness, cost, and adverse effects in chronic hepatitis $C$ several pre and on treatment predictors like normalization of ALT levels during therapy have been sought to detect patients with a good treatment response. ${ }^{16}$ Also, markers for determining a poor response early during therapy, such as the lack of EVR, have been recommended. Although in Pakistan some studies have attempted to report response rates to dual therapy of Sofosbuvir and Ribavirin therapy from various regions including Peshawar, most of them are based on qualitative or quantitative detection of HCV RNA irrespective of $\mathrm{HCV}$ genotype with limited or no focus on pre and on treatment predictors of SVR. Extended antiviral therapies have been associated with many side effects and medical costs together with factors that influence treatment response necessitates the identification of the predictive variables of reaching SVR. This will benefit the chronic HCV infected patients in selection of appropriate antiviral therapy as well as reduce HCV related morbidities in particular ethnic groups.

\section{OBJECTIVE}

The current study was designed to figure out the actual response rates of dual therapy with INF and RBV in HCV $3 a$ infected patients of Peshawar and to investigate the factors that could help predict response to antiviral therapy.

\section{METHODS}

\section{Patients}

A longitudinal study was conducted at IBMS, $\mathrm{KMU}$, Peshawar on 100 chronic hepatitis C 3a infected patients, who received a standardized treatment schedule at three tertiary care hospitals of Peshawar. After taking a written informed consent from each infected patient, patient's demographic data including age of the patient, gender and exposure to possible risk factors were recorded. The patients were selected for treatment based on detection of Anti HCV antibodies, elevated ALT levels, qualitative or quantitative Polymerase Chain Reaction for HCV viral RNA. Patients with normal Hemoglobin (Hb) level, Platelet and Total leukocyte Counts (TLC), normal Albumin and Creatinine values and with no evidence of decompensated liver disease on liver scan at baseline were included in the study. The study was approved by the local ethics committee and was conducted in accordance with the Declaration of Helsinki. Patients age, gender, HCV risk factors, $\mathrm{Hb}$, TLC, ALT, S. Albumin, Platelet count, Creatinine and viral genotype were recorded. Viral load was 
measured at baseline before initiating therapy, at 12 weeks and 24 weeks of therapy. Sample processing and baseline investigations including viral RNA quantification were carried out at each follow up visit in respective Hospitals.

\section{Therapeutic Regimen}

All the confirmed HCV genotype $3 a$ patients fulfilling the inclusion criteria received INF a-2a (INF-A 3MIU subcutaneously thrice a week) and Ribavirin (Ribazole, 400mg tablets) combination therapy for 24 weeks. Efficacy of treatment was assessed by measuring HCV viral RNA at start of therapy, at 12 and 24 weeks of therapy. Patients with undetectable HCV RNA after 12 and 24 weeks of therapy were labeled as having EVR and SVR respectively, while those with detectable HCV RNA at 24 weeks of therapy were considered NRs.

\section{Qualitative and Quantitative Detection of HCV Viral RNA}

Active HCV infection was ruled out using qualitative nested Polymerase Chain Reaction (PCR) targeting the 5 UTR region of HCV genome. All the qualitative PCR positive samples were quantified for HCV RNA by using Sacace HCV quantitative analysis kit (Sacace Biotechnologies Caserta, Italy). HCV genotype determination was carried out for each sample collected by Typespecific nested PCR based genotyping assay using type specific primers.

\section{Statistical Analysis}

SPSS version 20 was used for data analysis. The qualitative variables were described using percentage and the quantitative variables were described using the mean, median and standard deviation. The association between variables of interest among patients with SVR and NR patients was determined using Pearson chi-square test with 0.05 as level of significance. To identify the strength of association of EVR with SVR data was entered in a stepwise binary logistic regression model with EVR as predictor variable and SVR as response variable

\section{RESULTS}

\section{Characteristics of Chronic HCV Genotype} 3a Infected Patients Receiving Combination Therapy

Patients with confirmed status of HCV genotype 3a were prospectively evaluated for host and virus associated factors associated with treatment response. In a total of 100 patients who successfully completed therapy SVR was observed in $43 \%$ of patients, while $57 \%$ of Chronic HCV $3 a$ infected patients were NRs. Majority of the patients were male (60\%) out of which $43 \%$ achieved SVR. Moreover, in male patients having age less than 40 years, a higher SVR of $55 \%$ was observed as compared with a lower $45 \%$ response rate in male patients of age greater than 40 years. Similarly, when SVR for female patients was calculated, it was found out that among the $40 \%$ chronically infected female patients $43 \%$ achieved SVR. However, in females having age less than 40 years, SVR was $59 \%$ as compared to $41 \%$ response rate in females having age greater than 40 years. The mean baseline ALT level was higher in SVR group while the mean baseline viral load was higher in NR group. The implicated risk factors for HCV transmission were present in $23 \%$ of patients while $77 \%$ of them didn't give history of prior exposure to possible risk factors.

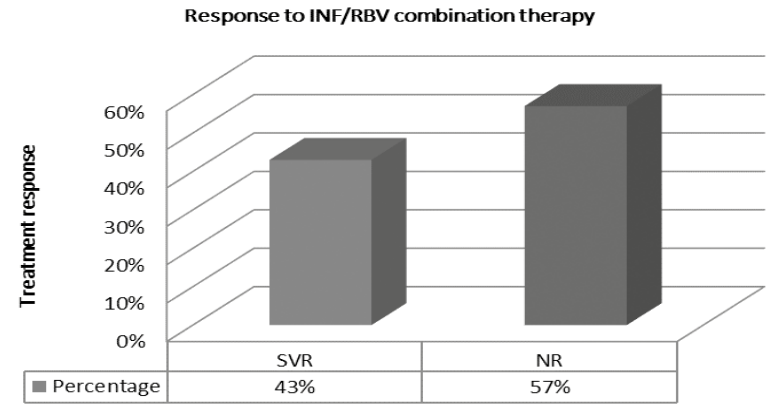

Figure-1. Treatment response of HCV 3 a patients to Combination therapy SVR (Sustained Virological Response), NR (Non-Responders)

\section{Association of Biochemical and Viral Profiles with Response to Anti-viral Therapy}

Various variables associated with therapy response are shown in Table-I. Baseline variables were repeated at 12 and 24 weeks of therapy and at 24 weeks of follow up. While the mean baseline ALT level of all the patients was $59.86 \pm$ 
39.0, higher than the upper limit of normal, the 24 weeks ALT levels were significantly lower among the patients with SVR as compared to patients with non-response (Pearson chi-square test, $p$-value $\leq 0.05)$. The median baseline HCV viral RNA in these patients was $725107 \mathrm{IU} / \mathrm{ml}$ (Range: 23541-23100000 IU/ml). Although statistically not significant, the baseline HCV RNA was higher in NR group (Pearson chi-square test, p-value $\geq$ 0.05), than those with SVR. For exploration of association between early viral kinetics and SVR, HCV viral RNA was quantified at 12 weeks after initiation of therapy. The association of EVR with SVR was found statistically significant (Pearson chi-square test, $p$-value $\leq 0.05$ ). To identify the strength of this association (EVR with SVR) data was entered in a stepwise binary logistic regression model with EVR as predictor variable and SVR as response variable. We found that EVR is predicting response to the effect of antiviral therapy $(\mathrm{OR}=2.8,95 \% \mathrm{Cl} 1.2-6.4$, $\mathrm{p}$-value $\leq 0.05)$.

\begin{tabular}{|l|c|c|c|}
\hline \multicolumn{1}{|c|}{ Variable } & SVR & NR & P-Value \\
\hline ALT(U/I) a & $32.6 \pm 16.9$ & $62.4 \pm 24.2$ & $\leq 0.05$ \\
\hline Viral Load b & & & \\
$<800000 I U / m l$ & $29 \%$ & $29 \%$ & $\geq 0.05$ \\
$>800000 I U / M I$ & $14 \%$ & $28 \%$ & \\
\hline EVR b & $73 \%$ & $27 \%$ & $\leq 0.05$ \\
\hline
\end{tabular}

Table-I. Analysis of factors associated with SVR and NR

a. Mean \pm standard deviation; b Percentage SVR, sustained of treatment response; ALT, alanine aminotransferase; EVR, early virological response.

Note: Differences between the group with SVR and NR were compared. Significant association was found between ALT levels and SVR (Pearson chi-square test, $p$-value $\leq 0.05$ ). Also, a significant association was calculated for EVR and SVR (Binary logistic Regression, 95\% Cl, OR $=2.8$, $p$-value $\leq 0.05)$.

\section{DISCUSSION}

The present study identified several patients and virus-related factors that can help predict SVR in
HCV 3a patients receiving combination therapy. SVR was observed only in $43 \%$ of patients with no obvious differences between male and female patients. Among various characteristics studied, age less than 40 years, normalization of ALT levels, a low baseline viral load and early viral clearance at 12 weeks (EVR) were associated with SVR. Statistically, a viral load of $\leq 800000$ $\mathrm{IU} / \mathrm{ml}$ at baseline, normalized ALT level at 24 weeks ( $p$-value $\leq 0.05$ ), and undetectable HCV RNA at 12 weeks ( $p$-value $\leq 0.05$ ) were identified as strong predictors of SVR. A careful analysis of previous studies from Pakistan regarding response to conventional or Pegylated INF/RBV combination therapy showed variable response rates ranging from $50-70 \% .{ }^{17-20}$ Dual therapies with DAAs like Sofosbuvir and Ribavirin showed better outcomes with SVR rates reaching $80 \%{ }^{21}$ In the present study we observed an SVR of $43 \%$. It has been observed that even in the same geographical location, the antiviral response may fluctuate in different patient populations, subject to patient characteristics and viral properties. Recently an important observation regarding nonresponse was the high frequency of IL28B NonCC genotype among HCV $3 a$ infected Pakistani patients. ${ }^{22}$ Recently Akhtar et al reported an SVR rate of $96.5 \%$ with 6 months therapy of Sofosbuvir and $\mathrm{RBV}^{23}$ The relatively lower response rates observed in the present study could be related to the emerging resistance in case of $\mathrm{HCV} 3 \mathrm{a}$ because of viral evolution and viral genetic mutations. This finding is also justified by the current large randomized controlled trials which have characterized $\mathrm{HCV} 3 \mathrm{a}$ as an INF and RBV resistant strain as compared to HCV 2 infections. ${ }^{24-26}$

In recent years, the recommendation to treat $\mathrm{HCV}$ genotype 3 infections for just 24 weeks has been challenged by the concept of tailoring the duration of treatment according to on-treatment viral response. EVR defined as undetectable viral RNA 12 weeks after treatment has been described as a strong predictor of achieving SVR ${ }^{27-29}$ in patients infected with HCV genotype $3 a^{30}$ Monitoring ontreatment viral response has been shown useful in individualizing therapy with a high chance to cure and to prevent therapy from being 
unnecessarily prolonged. ${ }^{31}$ Most of the studies reporting EVR as a predictor of SVR have been done in western countries with focus on genotype 1 infections. Results of present study were based on combination therapy in genotype $3 a$ infected patients and it revealed that patients who achieved EVR were more likely to have SVR than those who did not ( $p$-value $\leq 0.05$ ). An SVR of $73 \%$ was recorded for patients having EVR as opposed in only $27 \%$ SVR in patients without an EVR. In a recent meta-analysis Yee et al., observed an SVR rate of $85 \%$ in HCV genotype 2 and genotype 3 patients who achieved EVR, while 22.3\% SVR was recorded for patient without EVR. ${ }^{32}$ Similarly, Antonov et al., established a strong correlation between EVR and SVR ( $p$-value $\leq 0.011$ ) in HCV 1 infected patients. ${ }^{33}$ The findings of current study are thus compatible with previously published data establishing a positive relationship between the kinetics of the HCV RNA level early during therapy and probability of response to IFN based regimens.

To determine factors associated with therapeutic success various pre and on-treatment biochemical and virological features were evaluated. Normalization of ALT levels after therapy and a low viral load were recorded in SVR group. These findings are in line with regional studies reporting a relatively high response rate $(72.2 \%)$ for patient's less than 40 years of age. ${ }^{20,34}$ The ALT level at week 24 was significantly lower ( $p$ value $\leq 0.05$ ) for patients reaching SVR in our study. Normalization of liver enzyme levels following initiation of INF based anti-viral treatment has been reported in previous studies and may reflect response to therapy. In a study by Kelly et al., normal ALT levels early in the course of therapy (week 4) irrespective of raised baseline ALT and a low baseline viral load were found more frequently in patients who achieved SVR. ${ }^{35}$ A persistently elevated ALT level has been associated with ongoing viral activity in NR patients. ${ }^{36}$ Although the value of enzymatic response in predicting treatment response is inconclusive as compared to on-treatment viral kinetics, ALT is a simple, economical and commonly performed test that may be utilized in determining treatment efficacy.
Assessment of viral RNA load at various intervals of therapy is another important tool for predicting response to therapy. ${ }^{37,38}$ Though statistically not significant ( $p$-value $\geq 0.05$ ) our study showed a higher SVR for patients with low baseline viral load than those with NR patients as reported previously (194). This finding is also supported in a recent multivariate analysis evaluating various baseline variables for predicting response to antiviral therapy. ${ }^{39}$

\section{CONCLUSION}

The study concludes that pre and on-treatment monitoring of patients receiving anti-viral therapy is worthwhile. Patients having age less than 40 years, normalization of ALT levels at 24 weeks of treatment, a low viral load and an early viral clearance (EVR) at 12 weeks are important variables associated with favorable treatment response. In patients who do not reach EVR therapy should be individualized and the alternative treatment regimens should be considered.

\section{Funding Source}

This research did not receive any specific grant from funding agencies in the public, commercial, or not-for-profit sectors.

\section{Conflicts of Interest}

The authors declare no conflicts of interest.

\section{Acknowledgements}

We thank the patients who consented to participate in the study.

\section{Copyright $(15$ Dec, 2018.}

\section{REFERENCES}

1. Papadopoulos N, Argiana V, Deutsch M. Hepatitis C infection in patients with hereditary bleeding disorders: Epidemiology, natural history, and management. Annals of gastroenterology. 2018; $31(1): 35-41$.

2. Ansaldi F, Orsi A, Sticchi L, Bruzzone B, Icardi G. Hepatitis $C$ virus in the new era: Perspectives in epidemiology, prevention, diagnostics and predictors of response to therapy. World J Gastroenterol. 2014; 20(29):963352. 
3. Dhingra A, Kapoor S, Alqahtani SA. Recent advances in the treatment of hepatitis C. Discov Med. 2014; 18(99):2038.

4. Rizk HH, Hamdy NM, Al-Ansari NL, El-Mesallamy HO. Pretreatment predictors of response to PegIFN-RBV therapy in Egyptian patients with HCV genotype 4. PLoS One. 2016; 11(4): e0153895.

5. Murphy DG, Sablon E, Chamberland J, Fournier E, Dandavino R, Tremblay CL. Hepatitis C virus genotype 7, a new genotype originating from central Africa. J Clin Microbiol. 2015; 53(3):967-72.

6. Welsch C, Jesudian A, Zeuzem S, Jacobson I. New direct-acting antiviral agents for the treatment of hepatitis $\mathbf{C}$ virus infection and perspectives. Gut. 2012; 61 Suppl 1:i36-46.

7. Andriulli A, Mangia A, lacobellis A, Ippolito A, Leandro G, Zeuzem S. Meta-analysis: The outcome of antiviral therapy in HCV genotype 2 and genotype 3 infected patients with chronic hepatitis. Alimentary pharmacology \& therapeutics. 2008; 28(4):397-404.

8. Sharafi $\mathrm{H}$, Alavian SM, Keshvari M. Efficacy of 24-week pegylated interferon alpha and ribavirin combination therapy in highly selected patients infected with hepatitis C virus genotype 1. Hepatitis monthly. 2015; 15(1):e24955.

9. Seifert LL, Perumpail RB, Ahmed A. Update on hepatitis C: Direct-acting antivirals. World journal of hepatology. 2015; 7(28):2829-33.

10. Liu S, Watcha D, Holodniy M, Goldhaber-Fiebert JD. Sofosbuvir-based treatment regimens for chronic, genotype 1 hepatitis $C$ virus infection in U.S. incarcerated populations: A cost-effectiveness analysis. Annals of internal medicine. 2014 ; 161(8):54653.

11. Hashmi AH, Ahmad N, Riaz S, Ali L, Siddiqi S, Khan $\mathrm{KM}$, et al. Genotype CC of rs12979860 is providing protection against infection rather than assisting in treatment response for HCV genotype $3 a$ infection. Genes Immun. 2014; 15(6):430-2.

12. Umar M, Bilal M. Hepatitis C, A mega menace: A Pakistani perspective. J Pioneer Med Sci. 2012; 2(2):68-72.

13. Simmons B, Saleem J, Heath K, Cooke GS, Hill A. Long-Term treatment outcomes of patients infected with hepatitis $\mathbf{C}$ virus: A systematic review and meta-analysis of the survival benefit of achieving a sustained virological response. Clin Infect Dis. 2015; $61(5): 730-40$.
14. Namazee N, Sali S, Asadi S, Shafiei M, Behnava B, Alavian SM. Real response to therapy in chronic hepatitis $\mathbf{C}$ virus patients: A study from Iran. Hepatitis monthly. 2012; 12(9):e6151.

15. Tamori A, Enomoto M, Kawada N. Recent advances in antiviral therapy for chronic hepatitis C. Mediators of inflammation. 2016; 2016.

16. Davis GL, Lau JY. Factors predictive of a beneficial response to therapy of hepatitis C. Hepatology. 1997; 26(3 Suppl 1):122S-7S.

17. Waheed Y. Effect of interferon plus ribavirin therapy on hepatitis $C$ virus genotype 3 patients from Pakistan: Treatment response, side effects and future prospective. Asian Pac J Trop Med. 2015; 8(2):85-9.

18. Hassan M, Haq M, Amin M, Tahiurllah, Nawaz A, Ullah H. Association between baseline parameters and end of treatment response to combination of conventional interferon \& ribavirin in patients with chronic Hepatitis C. J Postgrad Med Inst. 2014;28(2):149-53.

19. Ahmad B, Ali S, Ali I, Azam S, Bashir S. Response rates of standard interferon therapy in chronic HCV patients of Khyber Pakhtunkhwa (KPK). Virol J. 2012; 9:18.

20. Idrees M, Riazuddin S. A study of best positive predictors for sustained virologic response to interferon alpha plus ribavirin therapy in naïve chronic hepatitis C patients. BMC Gastroenterol. 2009; 9:5.

21. Zanaga LP, Miotto N, Mendes LC, Stucchi RS, Vigani AG. Treatment of hepatitis $C$ virus genotype 3 infection with direct-acting antiviral agents. Braz $\mathrm{J}$ Med Biol Res. 2016; 49(11): e5504.

22. Farooqi JI, Farooqi RJ, Khan N, Muhammad R, Khan $\mathrm{N}$, Rehman A. IL28B polymorphism as a predictor of antiviral response in chronic hepatitis $\mathbf{C}$ genotype $\mathbf{3}$. Gomal J Med Sci 2014; 12:133-7.

23. Akhter TU, M. Khaar, HB. Aslam, F. Nisar, G. Naseer, A. Ahmad, S. Osama M. Sofosbuvir for the treatment of Hepatitis $\mathbf{C}$ genotype $\mathbf{3}$ infected patients in Pakistan. $\mathrm{J}$ of Ayub Med Coll Abbottabad. 2017; 28(4):884-9.

24. Tapper EB, Afdhal NH. Is 3 the new 1: Perspectives on virology, natural history and treatment for hepatitis $\mathbf{C}$ genotype 3. J Viral Hepat. 2013; 20(10):669-77.

25. Zeuzem S, Rizzetto M, Ferenci P, Shiffman ML. Management of hepatitis $\mathrm{C}$ virus genotype 2 or 3 infection: Treatment optimization on the basis of virological response. Antivir Ther. 2009; 14(2):143-54. 
26. Powis J, Peltekian KM, Lee SS, Sherman M, Bain VG, Cooper $\mathrm{C}$, et al. Exploring differences in response to treatment with peginterferon alpha $2 a(40 \mathrm{kD})$ and ribavirin in chronic hepatitis $\mathbf{C}$ between genotypes 2 and 3. J Viral Hepat. 2008; 15(1):52-7.

27. Ghany MG, Strader DB, Thomas DL, Seeff LB, American Association for the Study of Liver D. Diagnosis, management, and treatment of hepatitis C: An update. Hepatology. 2009; 49(4):1335-74.

28. Davis GL, Wong JB, McHutchison JG, Manns MP, Harvey $\mathrm{J}$, Albrecht J. Early virologic response to treatment with peginterferon alfa-2b plus ribavirin in patients with chronic hepatitis C. Hepatology. 2003; 38(3):64552.

29. Yu JW, Wang GQ, Sun LJ, Li XG, Li SC. Predictive value of rapid virological response and early virological response on sustained virological response in HCV patients treated with pegylated interferon alpha-2a and ribavirin. J Gastroenterol Hepatol. 2007; 22(6):8326.

30. Wu Q, Zhan FY, Chen EQ, Wang C, Li ZZ, Lei XZ. Predictors of pegylated interferon alpha and ribavirin efficacy and long-term assessment of relapse in patients with chronic hepatitis $C$ : A one center experience from China. Hepatitis monthly. 2015; 15(6): e28836.

31. Ferenci P. Predictors of response to therapy for chronic hepatitis C. Semin Liver Dis. 2004; 24 Suppl 2:25-31.

32. Yee B, Nguyen N, Zhang B, Lin D, Vutien P, Wong C, et al. Sustained virological response and its treatment predictors in hepatitis $C$ virus genotype 4 compared to genotypes 1, 2, and 3: A meta-analysis. BMJ Open Gastro. 2015; 2(1): e000049.
33. Antonov K, Jelev D, Ivanova A, Krastev Z. Predictors of sustained virological response (SVR) to pegylated interferon alpha (PEG-IFN a) and ribavirin (RBV) in patients with chronic hepatitis $\mathbf{C}$ infected with genotype. J IMAB. 2011; 17:197-9.

34. Aziz H, Raza A, Irfan J. Optimum predictors of therapeutic outcome in HCV patients in Pakistan. $J$ Med Virol. 2015.

35. Kelly E, Blach S, Razavi H, Cooper C. Interferon based hepatitis $C$ antiviral treatment outcomes may be predicted by alanine aminotransferase levels. Canadian Journal of Gastroenterology \& Hepatology. 2015; 29(8):407-8.

36. Thurairajah $\mathrm{PH}$, Thorburn $\mathrm{D}$, Hubscher $\mathrm{S}$, White A, Lai WK, O'Donnell K, et al. Incidence and characterization of serum transaminases elevations in pegylated interferon and ribavirin treated patients with chronic hepatitis C. Aliment Pharmacol Ther. 2007; 25(11):1293300 .

37. Kau A, Vermehren J, Sarrazin C. Treatment predictors of a sustained virologic response in hepatitis $B$ and C. J Hepatol. 2008; 49(4):634-51.

38. Di Bisceglie AM, Ghalib RH, Hamzeh FM, Rustgi VK. Early virologic response after peginterferon alpha$2 a$ plus ribavirin or peginterferon alpha-2b plus ribavirin treatment in patients with chronic hepatitis C. J Viral Hepat. $2007 ; 14(10): 721-9$.

39. Cavalcante LN, Lyra AC. Predictive factors associated with hepatitis $\mathbf{C}$ antiviral therapy response. World journal of hepatology. 2015; 7(12):1617-31. 


\section{AUTHORSHIP AND CONTRIBUTION DECLARATION}

\begin{tabular}{|c|c|c|c|}
\hline Sr. \# & Author-s Full Name & Contribution to the paper & Author $=$ s Signature \\
\hline 1 & Amina Gul & $\begin{array}{l}\text { Study desogn, experimental } \\
\text { work, data collection, data } \\
\text { analysis and write up. }\end{array}$ & \\
\hline 2 & Naheed Gul & $\begin{array}{l}\text { Study design, data collection, } \\
\text { data analysis and critical review. }\end{array}$ & . \\
\hline 3 & ljaz Ali & $\begin{array}{l}\text { Experimental work, data analysis, } \\
\text { write up. }\end{array}$ & \\
\hline 4 & Jawad Ahmed & Critical review and write up. & \\
\hline
\end{tabular}

